\title{
Destino Buenos Aires: tango-turismo sexual cinematografico*
}

\author{
Marta E. Savigliano**
}

Resumo

Buenos Aires disfruta de un boom turístico internacional y el tango figura predominantemente entre los motivos de atracción. ¿Qué buscan los viajeros foráneos en la experiencia tanguera? ¿Cómo saben qué les puede brindar específicamente un tango y el mundo del tango en general? ¿Qué placeres les ofrece el tango? No conforme con explicaciones sobre el carácter trascendental y universal del arte, este artículo explora los recursos sofisticados empleados en la narrativa cinematográfica para transmitir la seducción tanguera en el marco del erotismo de la diferencia cultural. Con este fin se analizan películas de tango recientes (The Tango Lesson de Potter y Tango de Saura) y del pasado (G ilda) en las que, en la exótica locación de Buenos Aires, la alteridad cultural se cruza con la alteridad de género (exacerbada por la presencia de femmes fatales) para desarrollar dramáticos y peligrosos desencuentros amorosos con final feliz. El tango, entonces, así apropiado, promete violentos huracanes emocionales, eróticamente docilizados por las leyes "universales" de la heterosexualidad y la homosocialidad. Una fórmula cinemática irresistible para el turismo sexual cultural.

Palavras-chave: Tango en el Cine, Turismo Cultural y

Sexualidad, Inter/Multi/Trans-culturalismo en el

Cine, Femmes Fatales.

\footnotetext{
Recebido para publicação em junho de 2005, aprovado em agosto de 2005.

** University of Califo mia, Los Angeles. martasa@arts.ucla.edu
} 
Tango-turismo sexual cinematografico

\author{
Destination Buenos Aires \\ Tango - Cinematographic Sexual Tourism
}

\begin{abstract}
Buenos Aires currently enjoys a boom in international tourism and the tango is undoubtedly a main local attraction. What are foreign tourists looking for in the tango experience? How do they know what is in a tango and in the tango world for them? What pleasures does the tango offer them? Unconvinced with settling explanations based in the universal and transcendental powers of art, the author explores the uses of tango in narrative cinema - in particular, the sophisticated ways in which the erotics of cultural difference frame tango-esque seduction. For this purpose, tango films of recent release (Potter's The Tango Lesson and Saura's Tango) and oldies (Gilda) are analyzed as stories that, taking place in an exotic Buenos Aires, weave intertwined dramatic plots of cultural and gender alterity - exacerbated by the presence of femmes fatales - , through dramatic and dangerous romantic disencounters with a happy end. Thus the tango, culturally appropriated, promises violent emotional turmoils, erotically tamed via "universal" laws of heterosexuality and homosociality. An irresistible cinematic formula for sex tourism.
\end{abstract}

Key Words: Tango in Film, Sexuality and Cultural Tourism, Cinema and Inter/Multi/Transculturalism, Femmes Fatales. 
Buenos Aires disfruta actualmente de un boom turístico internacional, y sin intenciones de quitarle importancia a sus múltiples bellezas y atractivos (vale aclarar que a precios altamente competitivos para el turista dolarizado o eurizado), experimentar el tango y su mundo continúa movilizando la imaginación aventurera del viajero. La oportunidad de observar y vivir la pasión tanguera en su lugar de origen figura, sin duda, como un motivo predominante en la elección turística del destino Buenos Aires. ${ }^{1} \mathrm{La}$ tango-propaganda más sofisticada, exitosa $\mathrm{y} / 0$ agresiva difícilmente alcanza para explicar esta fascinación. El tango promete "algo" que la propaganda turística difunde, pero que por sí sola no es capaz de crear. Hace años que me hago la misma pregunta: ¿Porqué les atrae el tango a los ajenos al mundo tanguero? ¿Qué es lo que buscan en la experiencia tanguera? ¿Qué placeres les ofrece el tango? Y ¿cómo saben estos foráneos lo que les puede brindar específicamente un tango y el mundo del tango en general? Podría conformarme con una respuesta enigmática, trascendental, como la que se dan tantos amantes del tango que señalan los poderes seductores de la danza, la música, la poesía... los misterios del arte. No lo he logrado. Y aquí estoy, nuevamente intentando entender qué es lo que transmite el tango, y particularmente cómo es que se producen y difunden estos deseos tanguísticos.

Con este propósito he elegido echar un vistazo a los usos del tango en la narrativa cinematográfica contemporánea y a los recursos sofisticados con los que se invita a los espectadores a conectarse a un tipo particular de placer que llamaré "turismo sexual cinematográfico informado" - en referencia al turismo sexual con una cierta sensibilidad "cultural". Dos películas recientes de tango, La Lección de Tango (1997) de Sally Potter y

\footnotetext{
${ }^{1}$ Sobre el auge del tango-turismo en Buenos Aires, la oferta de espectáculos de tango exóticos y el alquiler de tango-acompañantes por hora para turistas bailarines, ver un reciente artículo en Página 12 ("Buenos Aires y el boom de los espectáculos pensados en función del turismo"), 29 de Agosto del 2005 (www.pagina12.com.ar). Agradezco a Sarita Torres por la información.
} 
Tango-turismo sexual cinematografico

Tango. No Me Dejes Nunca (1998) de Carlos Saura, me provocaron esta idea: Para los ajenos al tango los placeres tangueros están estructurados en torno a la "cultura" (entendida como "diferencia") más que al sexo, o dicho de otro modo, es la erótica de la "diferencia cultural" lo que estructura los placeres tangueros en aquellos ajenos al tango. Se trata de un placer que anticipa a la experiencia del tango en sí misma; es decir, se trata de un placer ya generado y contenido en el deseo de gozar los placeres vividos por "otros" - el placer de la "diferencia".

En las mencionadas películas la erótica de la "diferencia cultural" se construye a través de los esfuerzos colaborativos y conflictivos de artistas contemporáneos argentinos e internacionales. La fabricación de un tango-producto con fines de circulación transnacional/transcultural es la finalidad compartida. La estrategia de marketing: Atraer a una audiencia global interesada en la diferencia cultural y comprometida en experimentar turismo urbano de entendidos (ya sea en vivo o cinemático) - es decir, turismo con seria información sobre la cultura visitada. Estas películas de tango, entonces, traen espectadores - los llamaré "turistas cinemáticos" - a Buenos Aires, abajo y al Sur del planeta, para presentarles escenarios tanguescos de profunda emotividad, creando un espacio para conexiones subjetivas a través y más allá de las diferencias culturales. El mensaje: Sumérjase en la alteridad cultural y, a pesar del shock y los traumas que sufrirá, emergerá enriquecido e inspirado. Mi propósito: Explorar cómo la comodificación de la "cultura" - en este caso, del tango - sirve para opacar la explotación del otro recurriendo a valores liberales benignos o benevolentes tales como el relativismo cultural acrítico codificado como multiculturalismo celebratorio. La "cultura" se ha convertido en un código cómodo para hablar sobre la "diferencia" dejando de lado la desigualdad. El punto clave a mi entender ha sido la presencia fugaz de los milongueros y especialmente de las milongueras (esas más bien poco glamorosas habitués noctumas del mundo tanguero de Buenos Aires, para quienes el tango es una fuente alternativa de 
identidad a la forma de vida burguesa globalizada a la que no pueden acceder). Su presencia marginal en las películas, presentada como referente legitimador de "autenticidad" y de "tradición", oscurece su participación crucial no sólo en hacer del tango lo que es y lo que representa, sino también como generosos maestros/as y consultores/as de los artistas (extranjeros y "nativos") que tienen el privilegio de recurrir al tango para contarnos (a los espectadores, turistas sexuales) sus propias historias conmovedoras. Una nota final a esta introducción: A consecuencia de esta revitalización de la apropiación cultural del tango (en la que colaboran, lo repito, tanto sectores "nativos" como de los culturalmente sedientos de lo que el mundo puede ofertar), una nueva ola de "folklore criollo" (música y danzas asociadas a las áreas rurales y a raíces nacionales "pre-tango") ha ganado popularidad entre los jóvenes argentinos que buscan otra expresión artística capaz de transmitir la "diferencia" (el desempleo, la creciente desigualdad en la distribución de la riqueza, las políticas neoliberales del FMI que reproducen el subdesarrollo al mismo tiempo que prometen el desarrollo) presente bajo la fórmula de "civilización o barbarie", una paradigmática falsa oposición que continúa guiando la historia argentina desde la concepción del estado-nación. Pero esta es otra discusión. ( $\mathrm{Si}$ bien Valentino bailando tango en ropajes gauchescos - algo así como una versión country-western del swing - sigue palpitando en la imaginación exotizante, diciéndonos que esta diferencia no tiene importancia.)

Los tangos han atraído a los productores y directores extranjeros (con lo que me refiero a los no argentinos 0 uruguayos) desde por lo menos los años 1920 y, me animo a decir, con el mismo efecto. ${ }^{2}$ (No intentaré adivinar sus

2 Sobre la presencia de temas argentinos (incluido el tango) en producciones de Hollywood ver CuRubeto, Diego. Babilonia Gaucha: Hollywood en la Argentina, 
Tango-turismo sexual cinematografico

intenciones.) La música extrañamente sincopada del tango ha sido utilizada para generar climas tenebrosos. Las tango-canciones (ya sea que se comprendan o no las palabras en español) evocan melodrama, y el tango-baile sugiere sensuales conflictos de poder. $H$ ilachas visuales y auditivas del género tango (el arte) se entretejen en narrativas de aventura ilícita, motivadas por ambiciones desmedidas (involucrando sexo y dinero) para generar tormentas emocionales. Un poquito de tango tanto en el cine de Hollywood como en el de autor ha venido a simbolizar transgresión ${ }^{3}$, pero también a anunciar algún tipo de contención, un retorno prometido a lo familiar habiendo ganado sabiduría, una moraleja. Los tangos están allí presentes, en el relato, para comunicar un coqueteo peligroso con el lado oscuro del deseo generado por una crisis existencial (envejecer, un matrimonio aburrido, la falta de inspiración) o para señalar las trágicas consecuencias existenciales de una circunstancia no buscada (el desempleo, la inmigración, la guerra) por sus víctimas. Cualquiera sea el caso, la ambición hace que las cosas vayan por mal camino para uno mismo o para otros, y los tangos figuran allí para sensualizar la caída de las víctimas en manos del victimario quien, al final, también resultará ser una víctima de las manos invisibles del deseo o del destino. Dramas y comedias cinemáticas hacen uso de ruidos e imágenes de tango para evocar las grandes fuerzas subterráneas de los mundos internos o externos, su poder irresistible al ser desatadas, y su peligrosidad cuando fuera de control. (Dramas tales como The Four Horsemen of the Apocalypse (Los Cuatro J inetes del Apocalipsis) (1921), Sunset Boulevard (1950), Gilda (1946), Isadora (1968), Last Tango in Paris

la Argentina en Hollywood. Buenos Aires, Planeta, 1993. Sobre el tango en la historia del cine ver Couselo, J orge. El Tango en el Cine. Historia del Tango, vol. 8 - El Tango en el Espectáculo -, Buenos Aires, Corregidor, 1977, pp.12891328.

3 Ver Foucault, Michel. A Preface to Transgression. En Bouchard, D. F. y Simon, S. (eds.) Language, Counter-Memory, Practice: Selected Essays and Interviews. Ithaca, N.Y., Cornell University Press, 1977, pp.87-111. 
Marta E. Savigliano

(El Último Tango en Paris) (1973), Alice (1990), y Scent of a Woman (Perfume de Mujer) (1992), toman en serio las fuerzas oscuras tanguísticas; comedias tales como Some Like It Hot (Una Eva y Dos Adanes) (1959), Addams Family Values (La Familia Addams II) (1993), y The Mask (La Máscara) (1994) emplean el grotesco tanguero para reír ante los poderes invisibles.) Los ruidos a tango se cuelan en los oídos de la audiencia anunciando momentos liminales, transiciones a terrenos peligros; las imágenes de tango son siempre bailadas, cuerpos dejados a su suerte, abandonados al placer, frecuentemente a puertas cerradas, en espacios oclusos, nocturnos, creando intimidad incluso en la presencia de extraños. Desde ese espacio de cautividad, los tangos, exóticos y eróticos, amenazan e inspiran vida y hacen de la vida un arte.

Los espectadores foráneos de cine (me refiero a aquellos que no "pertenecen" a las tierras latinoamericanas del tango) tararean un poco de tango y prueban un pacito de tango en sus mentes al salir del auditorio. Un poquitín de tango por acá y por allá, la sola mención de la palabra "tango" en el título o en los créditos musicales, y la fascinación se abalanza con sus impulsos contradictorios. Se necesita un algo de tango en la vida; pero no hay que pasarse de tangos. El tango, entonces, ha operado a lo largo de un siglo ahora como metáfora de crisis y enriquecimiento, adecuado a las sensibilidades burguesas (en la tango-música de cine, la melodía triste dociliza elegantemente el ritmo golpeador, insistente; el tango-baile de película es siempre glamoroso y refinado, conteniendo sobrecargas de energía con movimientos sedosos). El tango es un sazonamiento cultural adecuado al gusto de las audiencias maduras, y los directores de cine han promovido y han utilizado este, hoy en día, "arte universal" prestando poca atención a sus anclajes socio-políticos. Los tangos se han convertido en ingredientes de auto-reflexión, mecanismos para trabajar las interioridades. Los tangos ya han pasado a formar parte de la "condición humana". Los tangos son urbanos y lo suficientemente mundanos, suficientemente blancos, 
Tango-turismo sexual cinematografico

suficientemente con clase, sensuales antes que sexuales, y son heterosexuales.

Los tangos ya han pasado a constituir una tradición "civilizada"; jugueteando con el pasado y con su origen culturalmente específico, son conservadores con un toque salvaje. En los tangos el colonialismo ha sido superado hace tiempo, asimilado y olvidado. El imperialismo global y la poscolonialidad han traído el Norte y el Sur a un terreno neutral donde trozos desarraigados, libre-flotantes, de "cultura" circulan como fetiches de una amenaza exótica anticuada, que ahora nutren al multiculturalismo (la celebración de la diferencia cultural exenta de política.) Ahora los nativos quieren ser como los turistas, mientras trabajan para mantener viva la "diferencia" (entendida como cultura) con fines de trocar su entrada a los estratos mundiales de los privilegiados ofertando sus servicios "culturales".

El multiculturalismo es una modalidad del exotismo que implica el placer de colectar por el mundo experiencias "auténticas" (colectar objetos ya no alcanza). Los nativos (esos identificados como diferentes, independientemente de cuan híbridos sean) deben compartir y enseñar modos y costumbres preseleccionados (aquellos designados como "cultura" por los coleccionistas y preservacionistas) para ganarse la vida. A comienzos del siglo veintiuno ser un turista cultural en las tierras del tango es seguro y coherente. Se puede contar con la colaboración de los nativos; los nativos aprecian los intereses multiculturales y hasta tenemos nuestros especialistas (artistas y académicos) trabajando en "cultura" con ese fin.

En eso estamos entonces. Sally Potter y Carlos Saura, dos devotos a la supervivencia cultural artística, lanzan tours de tango cinemáticos casi simultáneamente (1997 y 1998, respectivamente). Inician una nueva era en la historia del cine de tango. Estas son películas totalmente dedicadas a la cultura tanguera (ya no simples 
retazos, referencias a este género artístico $).{ }^{4}$ Los usos metafóricos del tango aparecen situados en su contexto cultural, y los espectadores son trasladados para abajo, a la Argentina, para vivir una aventura tanguera llevados de la mano de un viajero cosmopolita entendido, un artiste. En ambos casos un artista (director de cine) se sumerge en el mundo del tango de Buenos Aires (locación originaria del tango) y vive una intensa historia de tango cuando su vida se entrelaza en relaciones íntimas, romántico-sexuales, con nativos tangueros - es decir con especialistas en tango, artistas entre los nativos; los únicos nativos culturalmente significativos merecedores del valioso tiempo del turista. (Los turistas siguen el mandato de la etnografía tradicional; ellos también hacen uso de "informantes clave".)

Desde el comienzo, ambas películas muestran la tremenda labor, la dedicación profesional del auteur que lucha por contar la historia de la cultura del tango (como un etnógrafo comprometido con la participación y la autorreflexión.) Las dos películas se inician en los escritorios de los especialistas culturales (los directores), guionando y sopesando la tarea de guionar sus historias tangueras y no pueden evitar colocarse como figuras centrales. (Esto por supuesto se atribuirá a los poderes irresistiblemente seductores del tango y de los tangueros, y a la particular capacidad cultural que posee el tango de provocar 0 revelar heridas existenciales.)

Sally, la protagonista de La Lección de Tango (interpretada por la misma Sally Potter), es una exitosa directora de cine británica quien se debate por guionar su próxima película y se distrae de sus arduas y solitarias jornadas de trabajo bailando tango de salón. En ese momento el trabajo y el placer estan divididos en su vida, y ella sufre una crisis de inspiración. Mario, el protagonista de Tango de Carlos Saura (interpretado por Miguel Angel Solá) es un artista nómade conflictuado (nacido en

\footnotetext{
${ }^{4}$ Naked Tango (Tango Desnudo) de Leonard Schrader fue un intento fallido más temprano (1989).
} 
Tango-turismo sexual cinematografico

Argentina, criado en España, vuelto a Buenos Aires tras un largo intervalo para encontrar a sus amigos desaparecidos bajo la represión política), quien esta viviendo una crisis propia de su mediana edad. Estos son artistas posfeministas ilustrados: él conectado con sus emociones y con cómo su vida personal (una relación amorosa fracasada) afecta su trabajo; ella agoniza con su trabajo y la pérdida de sus sensibilidades femeninas, su subjectividad dividida en tanto afecta su capacidad para crear y disfrutar de su arte que debiera ser coherente con su vida. Para Mario, sin embargo, la vida, más allá de su éxito artístico, no tiene sentido sin una relación romántico-erótica.

La Lección de Tango de Sally Potter es un relato de viajero autobiográfico apto para mujeres profesionales, solas y establecidas, que atraviesan la típica crisis de mediana edad de las herederas de la "liberación femenina". Su película sigue el programa de los manuales turísticos de tango especialmente diseñados para mujeres heterosexuales liberadas. Contiene verdaderas lecciones de tango (lecciones privadas costosas, y en ocasiones hasta con dos o tres bailarines profesionales a su disposición), y lecciones que advierten a las futuras turistas de tango sobre el campo minado emotivo que las aguarda en Buenos Aires. Las lecciones de tango de Sally exponen sus vulnerabilidades de feminista liberal. Ella busca a la Mujer perdida en la "tanguerina" (la tango-bailarina), un género dancístico adecuado a su madurez, sus imperfecciones, y que valora la "experiencia de vida". En el tango ella encontró un baile (hetero)sexy pero elegante que promete peligros posibles de enfrentar con el coraje necesario, y ahora ella esta dispuesta a compartir la historia edificante con sus espectadoras. El tango, como experiencia multicultural, puede enseñar. ${ }^{5}$ Los espectadores

\footnotetext{
5 Sobre los usos de la experiencia como testimonios y documentos ver las interpretaciones informadas y contrastantes de Joan Scott y Judith Oakley. ScotT, Joan. Experience. En ButLer, J udith y Scott, Joan. (eds.) Feminists Theorize the Political. New York, Routledge, 1992, pp.22-40; OAKLEY, Judith. Anthropology and Autobiography: Participatory Experience and Embodied
} 
son invitados a una sesión de concientización posfeminista. La Lección de Tango es un programa de rehabilitación para mujeres en riesgo de tango-adicción, y ofrecido en pantalla, como espectáculo, genera la misma extraña fascinación con lo patético que explotan los shows televisivos de testimonio. Sin embargo La Lección de Tango carece del sentido del humor característico de este género recreativo; ella controla demasiado bien todos los peligros. Sally aprendió la lección de tango (logró domesticar a los hombres del ambiente tanguero con una eficacia sin parangón para las mujeres nativas) y ahora está en condiciones de enseñarle a turistas y nativas.

Rewind. Sally es una artista talentosa, exitosa, en un mundo duro y ya no tan patriarcal, que ha perdido su lado tierno, femenino. Se halla dispuesta a explorar esa veta de su ser en tierras exóticas con hombres exóticos; reconoce con dificultad la presencia de mujeres en el mundo del tango, exceptuando su aspecto de rivales con las que jamás se mide. Puesta en tiempos de dislocación poscolonial, el exotismo ocurre donde sea que concurra la gente del tango. Las aventuras tangueras de Sally circulan entre Londres, Paris y Buenos Aires, y se desarrollan en una mezclada variedad de idiomas. Ella sufre la confusión. Embelezada por la actuación de Pablo (Pablo Verón) en el Folies Bérgere, se decide a iniciar una transacción con un nativo "cultural" que conmoverá su mundo. Sally quiere ser una bailarina (restablecer las conexiones cortadas con su cuerpo que representan su "interioridad" y su "verdadero ser", según las notas de guión de Potter), pero no abandonará su posición de poder

Knowledge. En OAKLeY, Judith y Callaway, Hellen. (eds.) Anthropology and Autobiography. London, Routledge, 1992, pp.1-28. También ver las provocadoras discusiones de Walter Benjamin acerca del concepto de experiencia. BenJAMIN, Walter. The Work of Art in the Age of Mechanical Reproduction. En ARENDT, Hanna. (ed.) Illuminations. New York, Schocken Books, 1969, pp.217-252 (traducido por Harry Zohn.), particularmente en "On some motifs in Baudelaire", pp.155-200. 
Tango-turismo sexual cinematografico

como directora de cine. ${ }^{6}$ Quiere sentirse como una mujer "verdadera" $y$, sin sorprender a nadie, termina enamorándose de un joven macho tanguero.

Sally seduce a Pablo presentándose como una directora de cine capaz de hacer de él una estrella a cambio de sus lecciones de tango. Las lecciones de tango (sorpresa, sorpresa) incluyen una relación romántico-erótica. Él la juega de amante, satisfaciendo las fantasías de Sally, hasta que tropieza con un límite. Habiendo dejado a su pareja de baile, Pablo invita a Sally a acompañarlo en un show de tango. Sally toca con las manos el cielo de la tanguerina. Las sesiones de entrenamiento y el espectáculo en sí mismo terminan siendo desastrosos. Ella no es lo suficientemente buena como bailarina de tango, supuestamente porque no es lo suficientemente sumisa como mujer. El hecho de que unas pocas lecciones técnicas, aun cuando agotadoras, no pueden prepararla para un espectáculo de tango a nivel profesional jamás se menciona. Por el contrario queda claro que una buena compañera de tango es una subordinada y que Sally no lo puede aceptar. Ella llora. El límite de la relación es cultural, inscripto en el tango. Sally no puede ser una mujer tanguera, una milonguera; pero ¿puede ser mujer?

Fast Forward. Sally y Pablo sostienen una conversación telefónica a los gritos, en francés:

Pablo: No sabés nada de tango.

Sally: $Y$ vos no sabés de mi.

Pablo: Tal vez no quiera saber más.

Sally: Entonces supongo que lo nuestro se acabó.

Pablo: ¿Qué es lo nuestro? ... Vos me has estado usando para vivir tus pequeñas fantasías.

\footnotetext{
6 "Se estimularon todos mis instintos de directora. Supe que podría trabajar con su presencia (...) Me estaba 'enamorando'." PotTer, Sally. The Tango Lesson. London, Faber and Faber,1997, p.ix.
} 
Marta E. Savigliano

Sally: No. No. Sos vos quien me ha usado. Nunca quisiste bailar conmigo. ... Me estuviste tomando el pelo para que un día te pusiera en una película y te hiciera una estrella.

Se aclaran las cosas. Deciden mantener separado "lo personal y lo profesional". Pablo propone "sublimar". ${ }^{7}$ (¿En qué estamos entonces? ¿EI deseo de Pablo existe? Entonces, ¿no la ha estado engañando? ¿O la estará engañando de nuevo para que no lo reemplace por otro bailarín de tango? Ambos los han visto circundando, a la pesca, como tiburones... Como Pablo hay muchos hombres de tango pero muy pocas mujeres como ella [consagradas directoras de cine interesadas en el tango]. También hay famosos actores que se prestarían a interpretar el rol protagónico de tanguero... Antonio Banderas por ejemplo. EI representante de Sally no puede creer que no aproveche la oportunidad para ofrecer el rol a un famoso actor y así asegurarse el éxito taquillero de su película de tango.) Sally se decepciona pero no traicionará a Pablo. Pronto nos daremos cuenta que ella tiene una misión que cumplir.

A esta altura la erótica del poder ha cambiado de rumbo. Sally asumirá su rol de directora de cine, mandoneará a Pablo, le enseñará a él y sus colegas tangueros (siguen ausentes las mujeres de tango) cómo ser actores. Ella escribe la historia, vende la historia, toma el rol protagónico de prima tanguerina, canta y actúa ella misma. (En la introducción al publicado guión menciona su decisión de contar esta historia "from the inside out", es decir, tal como fue: exponiendo los entretelones y confesando su interioridad. ${ }^{8}$ ) Pero Sally no esta dispuesta a convertirse en empresario a lo macho. Ella es una jefa poderosa pero con una diferencia; es mujer. No guarda resentimientos para con Pablo; ella se hace cargo de su propia confusión, de sus deseos

\footnotetext{
${ }^{7}$ La inclusión de terminología psicoanalítica en la conversación informal de un tanguero puede parecer fuera de lugar, pero en realidad apunta a la amplia popularidad del psicoanálisis en la Argentina.

8 PotTer, Sally. The Tango Lesson... Op. cit., p.ix.
} 
Tango-turismo sexual cinematografico

engañosos. Permanecerá emocionalmente vinculada a él, ya no como amante sino como figura materna. Le mostrará a Pablo su vulnerabilidad (la de él) y lo conducirá a superar su dolor. Sally es sabia y caritativa, una mujer empeñosa. Pablo será su obra de arte. (La introducción de Potter al guión cinematográfico concluye con las siguientes líneas: "El placer - llevado al extremo - se vuelve trabajo. Y el trabajo - llevado al extremo - se torna amor"). ${ }^{9}$

Rewind. La escena de epifanía: Sally y Pablo se encuentran luego de amargas disputas frente a la iglesia de St. Suplice en Paris. Como fondo, la pintura de J ob luchando con el Ángel de Delacroix. "Cuando se interpreta el tango - Sally le explica a Pablo y a la audiencia - Pablo es el Ángel y yo soy Jacob, luchando con él" (o con ella misma, nos explicará más tarde). Pablo y Sally adoptan las poses de luchadores para demostrar lo dicho.

Es una historia judía. ... a acob se da cuenta [continúa Sally] que nunca podrá vencer al extraño... simplemente porque J acob estaba luchando contra sí mismo. [Y continúa] Yo te he seguido en tu tango, Pablo. Pero para hacer una película tendrás que seguirme a mi.

Fast Forward. Ahora, en Buenos Aires, Pablo confiesa que está perdido; ya no se halla en su casa, no pertenece a ningún lugar. Pablo es un artista de tango, pero ya no un habitante del mundo del tango de Buenos Aires. Sally comprende sus tristes andanzas porque es judía; Pablo ha olvidado su identidad judía, un ancla espiritual que podría orientarlo en la vida. Nos hallamos en la escena final. Pablo pregunta:

Dime Sally, ¿qué significa sentirse judío? ... En realidad no pertenezco a Francia, pero tampoco ya me hallo aquí.

\footnotetext{
${ }^{9}$ ID., p.xii; ver también p.ix: "Era trabajo o amor? Puede ser que me halla enamo rado del trabajo?"
} 
Marta E. Savigliano

Tengo miedo. ... Tengo miedo de desaparecer sin dejar rastros.

Insiste en saber qué los ha hecho encontrarse, qué hizo que sus caminos se cruzaran. "¿Porqué nos conocimos?", pregunta, los ojos llenos de lágrimas. El aspirar a convertirse en una estrella de tango en el cine y figurar en una película de éxito no son razones suficientes. Sally ya nos había dicho (a los espectadores) que quería más; ahora nos enteramos que él también tiene otras ambiciones - según el guión de Potter. El es un macho pero también es vulnerable; y él no intentó manipular los sentimientos de Sally - lo que la haría quedar como una ingenua. Sally, entonces, le ha dado una lección: El estrellato es insuficiente. (Ella lo sabe. Es una estrella.) La búsqueda de Pablo es la búsqueda humana: dejar una huella en el mundo. Y ella le ha brindado esa oportunidad. Pause.

La Lección de Tango, la película, es el hijo (mas bien incestuoso) de Sally y Pablo: producto de su amor imperfecto, desencontrado. Al final, Sally le canta a Pablo, padre e hijo del tango de ella, una canción de cuna. Mujeres privilegiadas de la tierra, ustedes pueden lograr ésto en un tango-tour si asumen su rango, su sabiduría y sus contactos profesionales: Pueden jugar a la tanguerina; pueden acostarse con ambiciosos machos tangueros jóvenes y atléticos; pueden enamorarse y hacer que se enamoren de ustedes y de su poder (y nunca sabrán las verdaderas proporciones de la ecuación); pueden llorar y sentirse víctimas (puede que estén extrañando su aspecto femenino vulnerable); pueden practicar su generosa comprensión y hasta ofrecerle algunos consejos al tipo (pobrecito, él no se da cuenta); pueden llevarse de Buenos Aires un producto tanguero atractivo y vendedor (por ejemplo, a mi se me ocurrió una película de tango; ustedes pueden ver que se les ocurre); y una historia de tango (triste, enternecedora, pero sexy y llena de "potencia libidinal") para compartir con sus amigos y, eventualmente, contarles a sus 
Tango-turismo sexual cinematografico

nietos. Si están buscando una aventura tanguesca, acá tienen el manual. Stop. Eject. Cambiar casette.

Play Tango de Saura. La película de Saura exige más trabajo de los espectadores. Tango (estrenada en Argentina con el título de Tango. No Me Dejes Nunca) no es un manual turístico sino un manual de instrucciones para artistas - artistas qua etnógrafos. ${ }^{10} \mathrm{En}$ la película de Saura los espectadores son testigos de todos los pasos (editados y embellecidos por supuesto) requeridos en el desarrollo de un espectáculo de tango que simultáneamente será filmado. (Tango comienza y termina con tomas de una cámara que hace de panóptico vigilante, invisible para quienes están siendo filmados.) Los espectadores de la película son la audiencia privilegiada de un doble show: la película sobre la producción de una película sobre la producción de un show de tango. Se los involucra como espectadores de cine y como futuros turistas para quienes Mario (el director artístico interpretado por Miguel Solá) esta preparando un show de tango.

Pause.

Los espectadores de Tango son situados como etnógrafos amateurs (ya sean artistas, turistas, o una combinación de ambos) quienes tienen el privilegio de observar la producción de una obra de cine transcultural, una película etnográfica (documental ficcionada con una fuerte voz subjetiva) de una "otra" cultura convertida en una obra de arte con la participación de artistas nativos. ${ }^{11}$ El Mario de Saura es un artista como etnógrafo "nativo"

\footnotetext{
${ }^{10}$ Ver el artículo de Hal Foster y la colección de citas-meditaciones de J oseph Kosuth sobre el tema del artista como antropólogo (1993). Foster, Hal. The Artist as Ethnographer. En The Return of the Real: The Avant-Garde at the End of the Century. Cambridge, Mass., MIT Press, 1996, pp.171-204; Kosuth, Joseph. The Artists as Anthropologist. En Guercio, Gabriel. (ed.) Art After Philoso phy and After: Collected Writings, 1966-1990. Cambridge, Mass., MIT Press, 1993, pp.107-128.

${ }^{11}$ Para una discusión de las diferencias entre películas y documentales etnográficas asi como un tratamiento crítico del cine transcultural ver TAYLOR, Lucien. (ed.) Transcultural Cinema: David MacDougall. Princenton, Princenton University Press, 1998; Deveraux, Leslie y H ILman, Lucien (eds.) Fields of Vision:
} 
(un nativo distanciado de su cultura que informa sobre su cultura a extranjeros interesados en "otros" mundos). Sally sería la espectadora ideal de Saura, pero jamás hubiera conocido a Mario, el director del show de tango. Sally y los turistas cinemáticos de tango a los que ella se dirige vendrían a Buenos Aires para asistir a shows de tango como el de Mario (producidos especialmente para turistas), pero ella no hubiera estado interesada o en busca de artistas como él. Mario no pertenece lo suficiente al mundo del tango auténticamente "nativo". En Buenos Aires, la locación de Tango de Saura, el mundo de Mario no se cruzaría con el de Sally como colegas artistas; ellos son insuficientemente tangueros el uno para el otro. A pesar de la distancia "cultural" y de la distancia "Norte-Sur" que los separa (les recuerdo que ella es británica y él argentino), sus caminos no se cruzan en una historia de tango. Pertenecen demasiado a la misma clase. Ellos buscan el mismo tipo de alteridad y no son lo suficientemente "otro" el uno del otro.

Tango de Saura es entonces una película auto-reflexiva sobre la producción cinematográfica y auto-reflexiva sobre el artista en busca de inspiración que excava las raíces de su propia cultura en Buenos Aires con una audiencia "global" (como el "arte global") en mente. Play. Mario esta pasando por una crisis de mediana edad. Mientras lee el guión de una obra de tango que lo prepara para trabajar, se siente profundamente deprimido. Los espectadores, como etnógrafos amateurs, pronto aprenderán que sus penas son personales y políticas. Al retornar a Buenos Aires, Mario se encuentra con una ciudad en estado de negación luego de la dictadura militar. Sus viejos amigos están muertos y (Fast Forward) los productores de su tango show no quieren recordar el triste pasado. Rewind. Mario ha terminado una relación eróticoromántica con Laura (Cecilia Narova), una bailarina de tango

Essays in Film Studies, Visual Anthropology, and Photography. Berkley, University of California Press, 1995; y ToB IN G RonY, Fatima. (ed.) The Third Eye: Race, Cinema and Ethnographic Spectacle, Durham, N.C., Duke University Press, 1996. 
Tango-turismo sexual cinematografico

nativa profesional. Una escena casi de violación se desarrolla entre los dos cuando Laura le recuerda a Mario que ella no sólo tiene otro amante sino que además es feliz en esa nueva relación. (Entenderemos, si logramos juntar las piezas del rompecabezas, que la reacción violenta de Mario ante el rechazo de Laura se conecta con la rabia que Mario siente por la pasada represión política y la actual negación generalizada con que se encuentra.)

Fast Forward. Mario cojea de una pierna quebrada (tuvo un accidente automovilístico), mientras observa a Laura y Carlos (su nuevo amante interpretado por Carlos Rivarola) ensayando un apasionado tango de fantasía (un tango altamente coreografiado) para el espectáculo que él mismo dirigirá. Pause. Mario (su renguera nos da la pista), a diferencia de Sally, no aspira a ser bailarín. El no necesita "corporizar la experiencia" del nativo; Mario es un nativo (aunque quebrado). Mario contrata bailarines de tango para su show y elige a sus amantes entre ellos. Los bailarines de tango son artistas nativos (el profesionalismo afecta su verdadera naturaleza nativa, pero tengamos en cuenta que los artistas son especialistas "culturales" entre los nativos) quienes guiarán (por un sueldo) a Mario en su jornada existencial de índole cultural. Mario está preocupado por su envejecimiento, y busca confirmar su masculinidad en compañía de bellas bailarinas de tango que deberán estar dispuestas a acostarse con él, a enamorarse, y a ser felices junto a él. Stop. Eject. Cambiar de casette. Volver a La Lección de Tango de Potter. Play.

Pause. ¿Porqué no terminarían juntos el Mario de Saura y la Sally de Sally Potter? Mario no estaría interesado. Sally no es lo suficientemente vulnerable, joven, sexy o peligrosa. Ella no pertenece al mundo del tango. El nuevo objeto de amor de Mario, Elena (Mia Maestro), sí califica porque combina todas las características antedichas. A diferencia de Sally, Elena es una femme fatale del tango que aguarda ser domesticada (y salvada) por Mario. Hay un dato interesante aquí concerniente a la femme fatalidad que merece atención. Elena, objeto del deseo de Mario y potencial restauradora de su pierna/masculinidad quebrada, es 
Marta E. Savigliano

peligrosa porque es la mantenida de un mafioso entrado en años. (Este poderoso mafioso es un español-su acento lo distingue claramente del resto de los protagonistas con roles de argentinosrepresentando así el pasado poder colonial a través de la explotación sexual de las nativas.) La fatalidad de Elena (la atracción fatal que ejerce sobre Mario) responde, entonces, a su íntima asociación con un hombre que es doblemente valioso como rival (mafioso y colonizador) para Mario - quien busca confirmar su masculinidad nativa. Pareciera que, al menos en este contexto, las mujeres nativas calificarían como femmes fatales cuando bajo la tutela o sombra de hombres peligrosos. Si, como en este caso, los hombres representan el colonialismo, la fatalidad de ellas aumenta y con ello su atracción. La presencia de hombres peligrosos junto a femmes fatales parece aplicarse también a las mujeres no-nativas cuando la historia se desarrolla en locaciones coloniales o neocoloniales. Consideremos, por ejemplo, a Rita Hayworth en Gilda (1946). Buscar el casette de Gilda en el estante de videocasettes. Eject La Lección de Tango de Potter. Play Gilda.

Suficiente. Pause. Gilda es el objeto en disputa entre dos hombres extranjeros: el alemán con afiliaciones nazis dueño del casino en Buenos Aires, y un aventurero norteamericano, jugador perdido, a la deriva en un puerto Sudamericano. Johnny, el norteamericano, acepta trabajar para el ilícito empresario alemán como guardaespaldas de Gilda. Si bien la trama difiere enormemente de la de Tango de Saura (Gilda y J ohnny resultan ser viejos amantes a quienes, ignorando su pasado, reconecta el dueño nazi del casino, quien también es traficante de armas, inaugurando así un extraordinario triángulo amoroso del género noir), ambas películas coinciden en presentar sus femmes fatales como mantenidas de hombres maduros y peligrosos quienes, al principio, facilitan el encuentro (o rencuentro) con hombres jóvenes y atormentados quienes se volverán amantes románticos de ellas, y quienes jugarán de grandes rivales de esos jóvenes perdedores que buscan confirmar su masculinidad. Gilda y Elena, las femmes fatales en cuestión, en ambas historias hacen el papel 
Tango-turismo sexual cinematografico

de presas heterosexuales de un juego homosocial patriarcal. Buenos Aires figura en ambas películas de locación exótica, y por ende barbárica, del mundo, en donde se acumulan las actividades ilícitas a todos los niveles imaginables (corrupción política, tráfico de armas, juegos de azar, explotación sexual) y donde las ambiciones humanas no tienen límites éticos o institucionales. Los nativos, salvo unas pocas excepciones, sirven de telón de fondo. (En Gilda, la mucama de Gilda y el empleado del sanitario de hombres del casino hacen de voces paradigmáticas de sensatez y moralidad, privilegio de sus humildes ocupaciones; en Tango de Saura, los maestros de baile aparecen desarrollando responsablemente su tarea artística sin conflictos psicológicos o políticos, siendo estos últimos un privilegio reservado para Mario, el nativo quebrado.) Los roles protagónicos femeninos y femmes fatales de las historias, Gilda y Elena, son figuras emblemáticas atrapadas en esos momentos particularmente ambiciosos de sus vidas en que están aprovechando las ventajas de haber sido elegidas objetos de amor por hombres poderosos a quienes no aman y quienes no las hacen felices. Ambas mujeres son presentadas teniendo que hacer escojas existenciales dentro de los parámetros establecidos del mundo patriarcal, es decir eligiendo entre dos hombres que representan polos opuestos de poder/riqueza versus amor/cuidado (y este último no sin conflictos). Gilda y Elena, ambas en roles de artista (una, la experimentada bailarina/cantante; la otra, una aspirante a tanguerina profesional), personifican la parte feminizada del encuentro neocolonial (Gilda es una norteamericana; Elena, una argentina) luchando entre opciones diferentes que les permitan acomodarse al patriarcado capitalista, imperialista. Sus transgresiones nunca llegan a ser cortes posibles o resistencias atrevidas al sistema mundial establecido. Sus mejores apuestas (y las que conllevan el "final feliz" en ambas películas) están contenidas dentro de los límites del amor romántico heterosexual, la única cosa realmente importante. (G ilda regresará a los Estados Unidos en brazos de Johnny; Elena será rescatada por Mario, el 
Marta E. Savigliano

retornante y edificado nativo diaspórico.) ¿Qué género artistico podria transmitir esta trampa pasional mejor que el tango? ¿Qué cuerpo podría corporizar esta pulsión conflictiva mejor que una bailarina latina? ¿Quién podría competir con estos complejos estereotipos, sus redundantes resonancias, su domesticado exotismo, su poder evocativo establecido (obviamente se trata de comunicar problemas y conflictos pero tipificados y, por lo tanto, contenidos en un conflicto desconflictuado) con más éxito que estas bailarinas entrenadas para restablecer los sentimientos dañados de masculinidad? Stop. Eject. Rewind La Lección de Tango de Potter. Pause. Una Sally no puede restituirle la masculinidad a un Mario. Ella no necesita lo que él posee (dinero, genialidad). Ella es una competidora; es demasiado masculina (su edad, estatus, éxito, y sus contactos en Hollywood - éstos también se mencionan en la película.) Stop. Cambiar casettes. Play nuevamente Tango de Saura.

Mario está buscando una mujer que pueda brindarle la especificidad cultural que ha perdido; necesita una artista de tango nativa. Lo intenta con dos de ellas, una madura y una joven, en el transcurso de la historia. Elena, la más joven, dará resultado. La ingenuidad de la artista nativa constituye la diferencia dándole ventaja en cuanto a su feminidad más salvaje, menos corrupta. Pause. $Y$ en cuanto a Mario, él no es lo suficientemente auténtico para Sally. Hay muchos hombres como él en su mundo cotidiano. ¡Ella no hizo el esfuerzo de viajar hasta Buenos Aires para ésto! ¡La "pierna" de Mario está quebrada! EI no puede bailar. Ella no puede ser su víctima. El está demasiado informado y es demasiado políticamente correcto. Ella tampoco tiene nada que ofrecerle para rescatarlo. (Mario no necesita ni el dinero, ni el prestigio, ni el éxito de Sally.) Mario, como las mujeres del tango en la película de Sally, es invisible. Los artistas nativos quebrados como Mario y las artistas mujeres nativas como las bailarinas profesionales de tango no se adecuan a las transacciones monetarias/sexuales/ espirituales que propone Sally. Los Marios y las Sallys existen en el mundo del tango, pero no se ven porque 
Tango-turismo sexual cinematografico

están buscando la misma cosa que a ambos les falta. (En palabras de Lacan: la Mujer ${ }^{12}$ ) Stop. Eject. Cambiar casettes. Play La Lección de Tango.

Pause. Sally aspira a ser la Mujer ella misma encontrando un verdadero hombre que la haga vivir como tal (y esos hombres viven en otro mundo, feminizados por el mundo al que ella pertenece.) Sally tiene en mente un mundo como el del tango en el que los hombres disfrutan de bailar entre ellos; y los hace bailar para ella. (Queue up. Play la escena del trío masculino de tango.) Pablo (Verón), Gustavo (Naviera), y Fabián (Salas) bailan juguetones y salvajes hasta que Sally interviene. Ella, la tanguerina, pasa de los brazos de uno a los del otro, estableciendo el orden y la belleza en el mundo anárquico masculino. ${ }^{13}$ Sally quiere un hombre macho y vulnerable: un niño salvaje. Ella quiere un bailarín de tango, un artista nativo. Stop. Eject. Cambiar casettes. Play Tango de Saura.

Pause. Por el contrario, el Mario de Saura ni siquiera intenta bailar. Mario contrata a los hombres que bailarán con las mujeres de las que está enamorado. Observa a las mujeres en los brazos de ellos, alimenta con ello su deseo y se las lleva a la cama. EI tango es un juego amoroso que prepara para el sexual, un precalentamiento del que se ocupan otros hombres (los del tango) para que él luego disfrute del sexo. Mario se abstiene de bailar tango desde un principio. El es conciente de que su cuerpo renguea... Mario sabe que no puede competir con los bailarines de tango en su propio territorio. Recordemos que si bien todos ellos son artistas nativos, Mario es uno quebrado. (Él sí ve a los

\footnotetext{
${ }^{12}$ LACAN, J acques. God and the J ouissance of the Woman. En MITCHELL, J uliet $y$ ROSE, Jacqueline. (eds.) Feminine Sexuality: Jacques Lacan and the Ecole Freudienne. New York, W.W. Norton, 1985, pp.137-148. (Traducido por Jacqueline Rose.)

13 “Vueltas y saltos y figuras en el aire. (El baile) Se vuelve salvaje, anárquico y atlético. Su (la de los bailarines) frustración, energía, competitividad y exhuberancia finalmente toman forma (con la participación de Sally)". POTTER, S. The Tango Lesson... Op. cit., p.74.
} 
bailarines varones; Sally no ve a las mujeres del tango.) Pero Mario cree que su fantasía, su deseo, su genialidad superan (y son más valiosos) lo que su cuerpo indica. Los artistas nativos corporizan la "cultura", los artistas nativos quebrados como Mario crean el "arte global". Él no quiere hacer de sí mismo un espectáculo. $\mathrm{Ni}$ piensa en bailar. Los bailarines profesionales de tango, hombres y mujeres, son el repositorio de las fantasías sexuales de Mario y su material de trabajo.

Queue up a Carlos Rivarola y Julio Boca en su dúo de tango, y la coreografía grupal enteramente de varones sobre un piso semejante a un tablero de ajedrez. Play. Los bailarines de tango varones figuran aún más prominentemente en la película/ espectáculo de Saura/Mario que en la de Sally. Frecuentemente bailan juntos en coreografías grupales, pero también en dúos donde su entrenamiento "profesional" de bailarines supera sus connotaciones eróticas tangueras. ${ }^{14}$ La cámara hace una toma abierta larga, captando a los bailarines de cuerpo entero, siguiendo la trayectoria de sus movimientos sobre un espacio abierto, desnudo. Fast Forward.

(Avanzar cuadro a cuadro.) La escena enteramente femenina de bailarinas de tango, en franco contraste con la masculina, se centra en una seudo-erótica lesbiana (mujeres seduciéndose y hasta besándose entre ellas. $)^{15}$ La cámara toma detalles de la ropa interior que llevan las tanguerinas, de sus rituales de maquillaje, vestuarios espléndidos de los años 1920, largas boquillas de fumar y rostros insinuantes, prestando menos atención a la danza. (La película de Potter no presenta ningún tango entre mujeres.) Play. Pero los tanguerinos de Saura/Mario demuestran que sí saben bailar. Mario entrena personalmente a dos de ellos para un duelo de puñales (no de tango) como para que no queden dudas sobre la masculinidad de los bailarines y la suya propia. (Los espectadores/turistas no deben confundirse.) En

\footnotetext{
${ }^{14}$ Coreografía de J ulio Boca y Carlos Rivarola.

${ }^{15}$ Coreografía de Ana María Stekelman.
} 
Tango-turismo sexual cinematografico

esta escena, la única en la que Mario interviene como coreógrafo, establece sus conocimientos de la cultura nativa que, como artista nativo quebrado, es más amplia e informada, aunque menos auténtica, que las aptitudes culturalmente específicas de los bailarines de tango (quienes detentan una forma más simple que la suya de conocimiento). Pause. La fantasía de Mario sobre los hombres (nativos) es que cuando se los deja en sus propias manos (pensemos en los duelos masculinos) éstos lucharán a muerte. La heterosexualidad por ende es una necesidad. (En este punto Mario y Sally coinciden.) Y lo mismo se aplica a la homosocialidad. Cuando la heterosexualidad y la homosocialidad dejan de trabajar simultánea y cooperativamente, la vida (social) se vuelve un infierno.

Rewind.

Play. Mario avizora su próxima presa en un club tradicional de tango. (Aquí los espectadores como etnógrafos amateurs y turistas cinemáticos por única vez podrán echar un vistazo a los "auténticos" habitantes del mundo del tango: bailarines de tango liso de salón, entrados en años, poco atractivos; y las conversaciones de los actores indican cómo hay que apreciar la elegancia y la serenidad del tango popular. Estos son los verdaderos nativos en tren de baile; son precisamente quienes viven la "cultura" que los artistas nativos representan para la pantalla.) Elena, vistiendo un ceñido traje blanco y muy corto, es una "nena". Baila, ausente, abrazada a un viejo milonguero (bailarín de tango popular). (A esta altura de la narración, Elena es una verdadera bailarina nativa; Mario, con ayuda de los coreógrafos, la transformará en una artista nativa.) Un mafioso español, el dueño de la milonga o club de tango, le pide a Mario que le brinde a Elena, su amante, la oportunidad de presentarse a la audición para su futuro espectáculo de tango. Mario está destinado a la traición. La guerra por el amor de Elena ha sido silenciosamente declarada cuando ella inicia su entrenamiento privado para el show. 
Marta E. Savigliano

Mario seduce a Elena haciendo de ella una tanguerina. Pause. (¡El sueño de Sally hecho realidad! Pero ya expliqué porqué estaba escrito que Sally y Mario no se iban a cruzar.) Fast Forward. Luego de resistirse por un tiempo, Elena se muda con Mario al estudio. Se inician las negociaciones - mediatizadas a través de un encuentro heterosexual - entre un artista nativo cosmopolita, quebrado, y una artista de tango nativa poco experimentada. El guardaespaldas malevo del mafioso no los pierde de vista. Y la felicidad de Mario es asaltada por pesadillas Políticas con "P" mayúscula. No puede olvidar la guerra sucia y sus víctimas. Decide incluir en su show de tango una escena de un campo de concentración con coreografía tanguesca. ${ }^{16}$ Los productores del espectáculo (empresarios locales, varones y mujeres), atentos a las leyes del mercado, rechazan su idea y le aconsejan darle al público lo que éste espera: tango puramente recreativo. (Mencionan que ésta es una audiencia acostumbrada a la televisión y por lo tanto idiotizada.) Pause. La presencia del capital globaliza la narrativa, y la explotación del fetichismo cultural se torna evidente. Ingresa el artista como mesías. La misma senda recorrida en el caso de Sally, si bien ella la transita con menos grandilocuencia. Quitar Pause.

Mario, el artista, se rebela contra el mandato del capital y revela el lado oscuro de la historia ("Ios militares tocaban tangos a to do volumen mientras torturaban para sofocar los gritos de las víctimas.") Se niega a representar el tango aislado del contexto sociopolítico que informa el arte y la tragedia que éste expresa. Stop. Rewind. Play. Comienza la escena en el campo de concentración mientras Mario yace en la cama con Elena. Mario le explica (a ella, y con ella a la nueva generación de artistas nativos) la importancia de mantener los tristes recuerdos vivos. Elena entra en escena corriendo y cubriéndose los oídos, aterrorizada. Llora. Todas las víctimas de la escena bailada de tortura militar son mujeres. Todas la víctimas son mujeres. Todas las mujeres son

${ }^{16}$ ID. 
Tango-turismo sexual cinematografico

víctimas. Mario, el artista responsable, pospone sus deberes de amante responsable para completar su misión. Es el guardián autoproclamado de la memoria del poder. Mario lucha por separar lo personal de lo político, sus fantasías del mundo real, pero su mente artística sigue juntando las dos esferas. Las mujeres son víctimas. Fast-fast Forward.

La escena final de Tango de Saura/Mario describe la llegada de los inmigrantes al puerto de Buenos Aires alrededor del 1880. Los extras llenan la escena, en trajes de época. Los espectadores aprenden que estos nativos son híbridos dislocados, como Mario y como tantos de ellos. El malevo que trabaja para el mafioso ha sido contratado para esta escena. En medio de un cuadro de tango-danza primitivo, celebrando los orígenes (híbridos) del tango, el malevo en rol de inmigrante apuñala a Elena, quien también interpreta a una inmigrante. (Los espectadores se enteran que los humanos, no sólo los nativos, son salvajes. Todos somos víctimas de la naturaleza.) Para Mario ésta es la oportunidad de convertirse también en amante responsable. Corre al rescate de Elena de la "escena del crimen" para confirmar que se trata de una representación y para asegurarse (y asegurarle a ella) que en realidad está viva y que él la ama. Final feliz, artista responsable, humanidad unida en el dolor, y él se queda con la chica. Stop.

La película de Saura es sobre la producción: producción de una película (la cámara está presente, circulando en traveling, reflejada en los espejos); producción de un espectáculo de tango (el trabajo del director artístico, escenógrafos, coreógrafos, bailarines, cantantes, músicos, productores, etcétera); y producción de la creación artística. Sally se une al Mario de Saura en este punto, en sus roles de corporizar los vericuetos del hacedor de arte interesado en la especificidad cultural (en este caso, del tango) al servicio de los altos/vastos impulsos transculturales y humanísticos globales. Mario y Sally se posicionan como artistas preparados para el interculturalismo, es decir capaces de generar el entendimiento informado e iluminado entre culturas. 
Ejerciendo mediaciones acrobáticas, lidian con el exotismo y la alteridad (Sally con su judaísmo ancestral y su colonialismo británico); Mario con su conocimiento de cómo los ojos táctiles ${ }^{17}$ foráneos se posan sobre su propia cultura); también lidian con el auto-exotismo (el propio - Sally se ve tentada a hacerse "nativa", Mario a curar su nativismo "quebrado" - tanto como el autoexotismo de los artistas nativos, quienes se venden como representantes de una cultura "auténtica"); y lidian con el alto compromiso emocional personal y político que exige la inspiración artística. Sally y Mario son concientes de las maniobras del capital y del poder que ejerce en el mundo. (Ella sabe de su poder como cineasta británica en relación a un hombre del tango argentino; Mario sabe que sus contactos como artista cosmopolita lo posicionan como director artístico frente a los artistas nativos que contrata para su espectáculo de tango.)

Sin embargo, Mario y Sally no pueden dar cuenta de cómo esa diferencia (esa parte de la diferencia que no es "cultural" y que signa la explotación) afecta sus relaciones personales y sus compromisos con el arte. En ambos aspectos, sexo/amor y trabajo, ellos terminan por asumir una perspectiva universal - una movida de aufhebung (sublación o síntesis superadora) Hegeliana. Al final, los espectadores, ahora turistas cinemáticos o etnógrafos amateurs informados, aprenden que la diferencia - heterocultural y heterosexual - insufla pasión en la vida (privadamente, en sus camas; y públicamente, en el trabajo) y que esa es la condición humana. Ese es el mensaje universal del arte y del artista. Eso es un tango. Se cierra el círculo. Los espectadores, ahora edificados e informados con respecto a lo que el tango, en el fondo, "expresa" están adecuadamente equipados para un tour sexual de tango en Buenos Aires. Y harán del turismo una obra de arte.

En conclusión, el paradigma tan convincente y regularmente aceptado del "arte como expresión universal" funciona, en los

\footnotetext{
${ }^{17}$ Sobre la "tactilidad" óptica ver B ENJAMIN, W. The Work of Art... O p. cit.
} 
Tango-turismo sexual cinematografico

términos de J acques Derrida ${ }^{18}$, como un pharmakon (una droga que cura al tiempo que envenena). Potter y Saura, cada uno a su modo, trabajan mucho para crear historias de tango con "sensibilidad cultural". (Sally sigue un programa posfeminista; Saura sigue una agenda posmoderna, informada en lo históricopolítico.) Sin embargo, la necesidad de llegar al espectador a través de la identificación personal/psicológica - una receta humanística en las artes - termina por deshacer todo el esfuerzo invertido en señalar la diferencia cultural. Situándose ellos mismo al centro de estos relatos de tango como protagonistas y como traductores culturales, desplazando a las márgenes a los verdaderos protagonistas del mundo del tango (los milongueros, cuyos rasgos y comportamientos son más difíciles de digerir para los turistas cinemáticos), Potter y Saura invocan el universalismo a través del arte. Así es como el Arte se torna en un espacio sobrenatural, fuera de este mundo, en donde la "comprensión" transcultural es posible. Invito a los lectores a hacer el ejercicio de revisar esta lógica persuasiva que sugiere que las "culturas" están ahí, en el mundo, para nuestro provecho -nosotros, los privilegiados y culturalmente sensibles turistas/etnógrafos/ artistas. El que hoy en día identificar "culturas" sea, desde el vamos, hecho con la idea de apropiarse y sacar ganancias de lo otro. Y que la noción del Arte - como signo de lo sublime y universal - ayuda a enmascarar el lado oscuro (explotación, dominación, desigualdad) de la "diferencia cultural" que no deseamos confrontar: los privilegios que rehusamos reconocer y de los que no queremos hacernos cargo.

\footnotetext{
${ }^{18}$ Derrida, Jacques. Plato's pharmacy. En Disseminations. Chicago, Chicago University Press 1981, pp.61-172. (Traducido por Barbara J onson.)
} 
Marta E. Savigliano

Filmografía

Addams Family Values (La Familia Addams II). 1993. Dirigida por Barry Sonnefeld; personajes de Charles Addams. Protagonizada por Anjelica Huston, Raul J ulia y Cristina Ricci. Paramount (Estados Unidos).

Alice. 1990. Escrita y dirigida por Woody Allen. Protagonizada por Mia Farrow, J oe Mantega y William Hurt. Orion (Estados Unidos).

The Four Horsemen of the Apocalypse (Los Cuatro Jinetes del Apocalipsis). 1921. Dirigida por Rex Ingram sobre guión de J ohn Mathis. Protagonizada por Rudolf Valentino y Alice Terry. Metro (Estados Unidos).

Gilda. 1946. Dirigida por Charles Vidor sobre guión de Marion Parsonnet. Protagonizada por Rita Hayworth como Gilda, Glenn Ford como Johnny Farell, y George MacReady como Ballin Mundson. Columbia Pictures (Estados Unidos).

Isadora (La Vida de Isadora Duncan). 1968. Dirigida por Karen Reisz, basada en My Life de Isadora Duncan. Protagonizada por Vanesa Redgrave como Isadora, Jason Robards e Ivan Tchenko. Universal (Estados Unidos).

The Mask (La Máscara). 1994. Dirigida por Chuck Russell sobre guión de Michael Fallon. Protagonizada por J im Carey y Caron Diaz. New Line Cinema (Estados Unidos).

Last Tango in Paris (El Último Tango en Paris). 1973. Dirigida por Bernardo Bertolucci sobre guión de Bertolucci y Franco Arcalli. Protagonizada por Marlon Brando y María Schneider. PEA Artiste Associe/ United Artists (Italia/Francia).

Naked Tango. 1989. Dirigida y escrita por Leonard Schrader. Protagonizada por Mathilda May y Esai Morales. Scotia Internacional (Estados Unidos).

Scent of a Woman (Perfume de Mujer). 1992. Dirigida por Marin Brest sobre guión de Bo Goldman. Protagonizada por Al Pacino, Chris O 'Donnell y Gabriel Anwar. United Artists (Estados Unidos).

Some Like It Hot (Una Eva y Dos Adanes). 1959. Dirigida y escrita por Billy Wilder. Protagonizada por Tony Curtis, Jack Lemon, Marilyn Monroe y J oe. E. Brown. United Artists (Estados Unidos). 
Tango-turismo sexual cinematografico

Sunset Boulevard. 1950. Dirigida por Billy Wilder sobre guión de Wilder, Charles Bracket y D. M. Marshman. Protagonizada por G loria Swanson y William Holden. Paramount (Estados Unidos).

The Tango Lesson (La Lección de Tango). 1997. Dirigida y escrita por Sally Potter. Protagonizada por Sally Potter y Pablo Verón. Sony Pictures Classic.

Tango. No Me Dejes Nunca. 1998. Dirigida y escrita por Carlos Saura. Protagonizada por Miguel Angel Solá, Mia Maestro y Cecilia Narova. Sony Pictures Classic. 